\title{
The contributions of diverse sense organs to the control of leg movement by a walking insect
}

\author{
H. Cruse, J. Dean, and M. Suilmann \\ Fakultät für Biologie, Postfach 8640, Universität Bielefeld, D-4800 Bielefeld, and Fachbereich Biologie, \\ Universität Kaiserslautern, Federal Republic of Germany
}

Accepted February 3, 1984

Summary. During locomotion, stick insects Carausius morosus, place the tarsus of the rear leg near the tarsus of the ipsilateral middle leg, whatever the position of the latter. This adjustment by the hind leg requires that it receive information on the actual position of the middle leg tarsus. It is shown by ablation experiments that such information is contributed by the following proprioceptors of the middle leg: the ventral and dorsal coxal hairplates, the coxal hair rows, the trochanteral hairplate and the femoral chordotonal organ. Additional information comes from other, as yet unidentified, sense organs. Several alternatives are considered to explain how the signals from the diverse sense organs of the subcoxal joint might be combined in computing the target position for the protracting hind leg. The experimental results support the hypothesis that the signals are added nonlinearly and that a signal deviating from the majority pattern is weighted less.

\section{Introduction}

It is a common phenomenon that proprioceptive organs are arranged in parallel and appear to measure more or less the same parameter. This is particularly true for position-measuring sense organs in the walking legs of arthropods. For example, a recent survey of sense organs that register movement of the subcoxal joint in locusts listed several internal organs - chordotonal organs, strand receptors and multipolar nerve cells - plus external organs - hairplates (HP) and hair rows (HR) (Bräunig et al. 1981; Pflüger et al. 1981; Hustert

Abbreviations: $c x H P v$ ventral coxal hairplate; $c x H P d$ dorsal coxal hairplate; $\operatorname{trHP}$ trochanteral hairplate; $H R$ hair row; feCO femoral chordotonal organ; AEP anterior extreme position et al. 1981). Because joint position can be completely described with just three parameters, there are many more proprioceptors than parameters to be measured. This surplus of sense organs might function as a system of range fractionation. It could also provide redundancy to compensate for failure of individual organs. To date, nothing is known about how the information provided by these sense organs is evaluated by the central nervous system (CNS) to control active movements of the legs. This question is the subject of the present experiments on the control of leg protraction in the stick insect. As in the locust, the proximal leg joints of stick insects are provided with many proprioceptors. However, the stick insect offers a unique advantage for investigating such active movements. The most common problem in such investigations is that the target of an animal's movement is unknown; for the stick insect, the target of the leg protraction is known. When the hind leg swings forward during walking, it places its tarsus near the tarsus of the ipsilateral middle leg (Cruse 1979; Dean and Wendler 1983), i.e. the hind leg uses the position of the middle leg tarsus as a target. When the animal walks on a treadwheel, the position of this 'target' can be manipulated by the experimenter.

This experimental paradigm has an additional advantage for ablation experiments. When the manipulations to modify a sense organ are on a leg whose movement is subsequently measured, any observed changes might be due to secondary effects, which may confound the interpretation of the basic change in position signals. Examples of such effects are the decrease in the spontaneous discharge rate of the slow extensor tibiae motoneuron after cutting the apodeme of the femoral chordotonal organ in stick insects (Cruse and Pflüger 1981) or the decrease in overall walking activity following ablation of myochordotonal organs in 
the legs of a crab (Fourtner and Evoy 1973). In our test situation, however, the position-measuring sense organs that provide the target information can be manipulated without inducing tonic changes in the leg that performs the active movements or affecting its ability to move to an intended target. Ablations of different external sense organs in the middle leg can be combined to examine how the commands from separate sense organs act together to provide the target information for the active movement of the hind leg during the swing stroke.

\section{Materials and methods}

Adult female stick insects (Carausius morosus) were used for the experiments. Each animal was fixed dorsally in a holder with the longitudinal axis of the body horizontal. All legs were free to grasp a styrofoam treadwheel (diameter $38.5 \mathrm{~cm}$, width $9 \mathrm{~mm}$, moment of inertia $720 \mathrm{~g} \cdot \mathrm{cm}^{2}$, static friction $80 \mathrm{mg}$ ). The distance between the insect's body and the wheel was fixed. For each measurement the right middle leg of the stationary insect was first placed on a rigid horizontal platform beside the wheel. This platform was held in a manipulator and covered with a millimeter graph paper. The target coordinates $(x=0$, $y=0$ ) were defined as the middle leg tarsus position for which the femur was held horizontal and perpendicular to the longitudinal axis of the body while the tibia was directed vertically downwards. Other target positions $(10 \mathrm{~mm}$ anterior, $10 \mathrm{~mm}$ posterior, $5 \mathrm{~mm}$ medial, $5 \mathrm{~mm}$ lateral) were obtained by moving the platform with the middle leg tarsus the corresponding amount and direction from the 'zero' position by means of the micromanipulator.

After the middle leg was placed in the desired target position, the animal was lightly touched on the abdomen to initiate walking. Only the first step of the ipsilateral hind leg was evaluated. During the swing movement the animals placed the tarsus of the hind leg on the platform beside the tarsus of the middle leg (Cruse 1979). The distance between the distal ends of the tibiae (which are better measures of proximal joint configurations than the tarsus tips) of both legs was measured in the direction perpendicular $(x)$ and parallel $(y)$ to the longitudinal axis of the body. The values of $x$ and $y$ were defined as positive when the tarsus of the hind leg was distal and posterior, respectively, to the tarsus of the middle leg. Between measurements the platform was moved away from the wheel, and the animal stimulated to walk several normal steps.

The experimental procedure was as follows. First, 20-30 steps were measured for the intact animal. Then one or more sensory organs were ablated; the animal was allowed to recover for 1 day and then at least a further 20-30 steps were measured. Preliminary experiments showed that the effects of an operation were unchanged for at least 6 consecutive days following the operation (Suilmann 1981). For about $50 \%$ of the animals, operation and measurements were performed by different persons and the experimenter was not informed about the kind of ablation made. In some experiments two groups of sensory hairs were removed consecutively in the same animal (results in Table 3 and part of Table 4). In these cases the temporal order of the different ablations was changed in some animals and no differences were found.

Phasic input from the femoral chordotonal organ was removed by cutting a small window in the distal femur and sectioning the receptor apodeme (Bässler 1965). The sensory hairs from one or more organs were removed under a dissecting microscope $(50 \times)$ using a fine scalpel. If not otherwise stated, ablation of the ventral coxal hairplate, cxHPv, includes removal of adjacent hairs on the trochantin. The trochantin is a small, thin sclerite which articulates caudally with the coxa just ventral to the cxHPv and rostro-dorsally with the pleuron (see Fig. 1). It should not be confused with the trochanter, the second leg segment, which articulates distally on the coxa and is fused with the third segment, the femur. The removal of group 1 hairs (G1) in the cxHPv (Tatar 1976) posed special problems. For critical cases the success of this operation was controlled under a microscope $(200 \times)$ and appeared complete. Nevertheless, a post-measurement examination of three animals using a scanning electron microscope (SEM) revealed six to eight hairs of the cxHPv G1 very near the articular membrane that were not fully ablated.

Results were tested for significant differences using the Kolmogoroff-Smirnow test because the data differed from a normal distribution. However, this difference was not very great, and so standard deviations are presented to show the variability in the results.

To complement the behavioural experiments, the relation between leg position and stimulation of individual sense organs was observed under a dissecting microscope $(50 \times)$. Animals were fixed on a holder similar to that used for experimental testing but with one middle leg restrained either at the tarsus or at the femur in such a way that the leg could be rotated forward and backward at a fixed elevation. At each position, the extent to which each sense organ was covered by the flexible articular membrane was noted. Only the range of joint or leg positions monitored by each organ will be presented here; this is sufficient for interpreting the effects of ablating entire sense organs. A more detailed account of the coding of leg position by the hair rows is in preparation.

\section{Results}

\section{Functional anatomy of sensory hairs in the subcoxal and the coxo-trochanterofemur joint}

The three proximal leg joints allow the leg to function as a strut of variable length moving within a solid angle with its origin at the dorsal coxal articulation. Thus the action of the two proximal joints is most directly represented in polar coordinates. Nevertheless, the functionally important parameter, tarsus position, is better measured in terms of the standard orthogonal coordinates, especially when the goal is to compare the tarsus positions of two legs. However, it should be remembered that the three leg joints do not correspond to the coordinate axes. Alteration at a single joint can produce changes in all three coordinates, depending on the configuration of the other joints.

Previous investigators have described the anatomy of the two proximal leg joints studied here (Wendler 1964; Cruse 1976; Graham and Wendler 1981) and have identified three hairplates (Wendler 1964) and four hair rows (Bässler 1965) monitoring the position of these joints. Both the ventral coxal hairplate, $\mathrm{cxHPv}$, and the trochanteral hairplate, 
a)

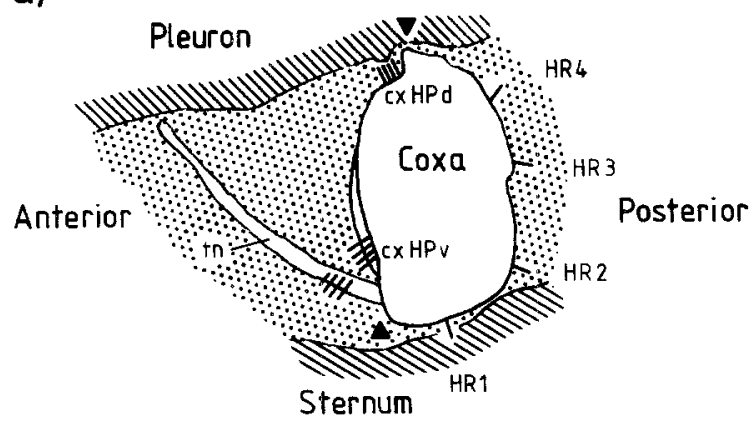

b)

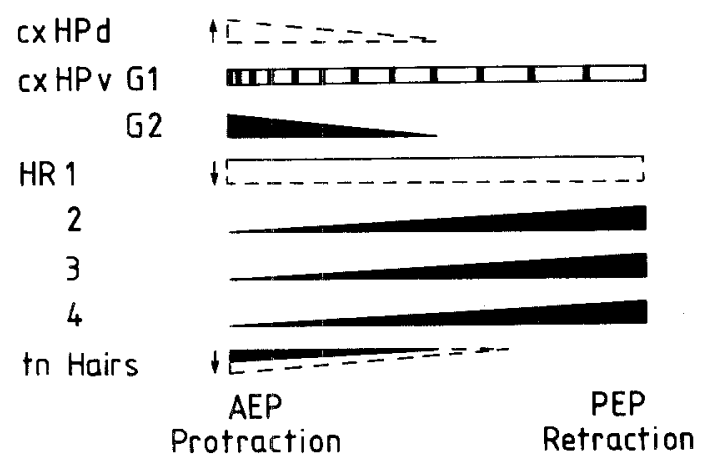

Fig. 1 a, b. Location and activity characteristics of hair sense organs at the subcoxal joint. a Lateral view of the left mesothorax with the coxa illustrated in cross section. The pleural and sternal sclerite margins are shaded; the flexible articular membrane is stippled. The coxa articulates with the pleuron and with the trochantin $(t n)$ at the points indicated by the black triangles. The trochantin articulates anteriorally with the pleuron, forming a strut which allows the ventral coxal articulation to move perpendicularly to the plane of the body surface. The dorsal and ventral coxal hairplates, cxHPd and $c x H P v$, are compact clusters of hairs near the proximal rim of the coxa. They are shown as groups of short lines, as are the irregularly dispersed hairs on the ventral trochantin. The four hair rows, $H R 1-4$, which run longitudinally on the posterior coxa, are represented by single lines. b Pattern of stimulation for the different sense organs for coxa angles between the anterior extreme point $(A E P)$ and the posterior extreme point $(P E P)$. For each organ listed at the left, the thickness of the black wedge qualitatively reflects the number of stimulated hairs. $c x H P v$ is divided into two groups of hairs ( $G 1$ and $G 2$ ); the hairs of $c x H P v$ G1 all contact the joint membrane at all leg positions (bar of constant thickness), but the amount of their deflection probably increases with increasing protraction (indicated by the increasing density of lines within the bar). Dashed lines are added where large changes in the number of stimulated hairs follow either abduction or adduction of the ventral coxal articulation (upward or downward arrows, respectively; e.g. adduction increases the number of stimulated hairs both for $H R 1$ and for the tn Hairs)

trHP, can be subdivided into two groups of hairs (Tatar 1976). One group (G1) is a closely set row standing in a narrow groove at the margin of the respective sclerite adjacent to the articular membrane, whereas the second group (G2) consists of scattered hairs set on the sclerite flange slightly removed from the articular membrane.

Figure 1 summarizes the location of these organs and schematically illustrates the range of positions they monitor. For protraction and retraction about the semi-vertical axis of the subcoxal joint, the cxHPv and the three dorsal hair rows, HR2-4, act antagonistically. During retraction the number of deflected hairs increases in HR2-4 and decreases in cxHPv G2 (black wedges in Fig. 1b). Each hair row measures virtually the entire range of leg positions. The proximal hairs generally are covered even at the anterior extreme while the most distal hairs of rows 2 and 4 are only deflected near the posterior extreme, if at all. In contrast, the anterior joint membrane stands clear of cxHPv G2 when the coxa is retracted beyond about $90^{\circ}$. Abduction or adduction of the coxa, which tilts this semivertical axis, does not visibly alter the configuration of the fold of the articular membrane over the cxHPv. This membrane segment is attached to the trochantin and thus moves in conjunction with the trochantin-coxa articulation. Adduction of the coxa does alter the details of hair deflection in HR2-4, but for normal coxa positions these rows continue to measure virtually the full range of leg movement. All the hairs of cxHPv G1 maintain contact with the joint membrane at all positions (Tatar 1976). Thus there is no change in the number of active hairs (bar in Fig. 1 b), but it is possible that through changes in the level of activity this group can monitor the full range of leg positions (density of lines within the bar in Fig. 1 b). Like cxHPy G2, the dorsal coxal hairplate cxHPd stands completely uncovered for leg positions posterior to about $90^{\circ}$ (dashed wedge in Fig. $1 \mathrm{~b}$ ); unlike cxHPv G2, it is strongly affected by tilting of the semi-vertical axis in so far as this changes the depth to which the coxal condyle is pressed into the pleural socket. When adduction of the coxa draws the dorsal articulation apart, the greater part of cxHPd remains uncovered even for the most anterior leg positions (base line in Fig. 1 b). In contrast, when the dorsal articulation is pressed tightly together, cxHPd is entirely covered at the most anterior leg positions.

The hairs on the trochantin are deflected by folding of the subcoxal membrane ventral to the trochantin. As for the hairs of the cxHPd, the extent to which these hairs are deflected reflects both leg protraction and adduction. Increasing adduction, which moves the trochantin-coxal articulation in under the laterosternite, extends the range over which hairs are deflected (dashed area in Fig. 1 b). Similarly, the number of deflected hairs 
a) HP
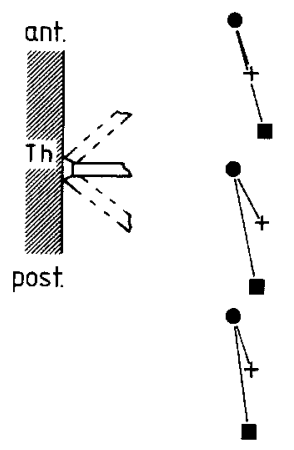

- R2 (target)

+ R3 AEP: control

- R3 AEP: $\exp$. b) $H R$
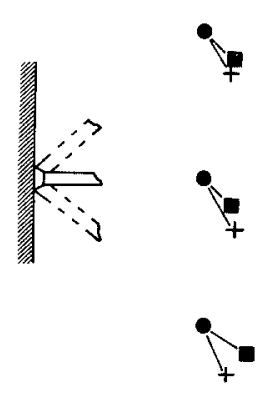

$10 \mathrm{~mm}$ c) $\mathrm{HP}, \mathrm{HR}$

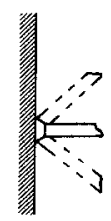

$\overrightarrow{y^{x}}$
Fig. 2a-c. Combined effect of hairplates and hair rows on the endpoint of the hind leg relative to the position of the middle leg as viewed from above. The three columns present the changes for removal of (a) hairplates $(H P)$,

- (b) hair rows (HR) and (c) both (HP, HR) on the middle leg. Before and after each operation animals were tested with the middle leg positions $10 \mathrm{~mm}$ anterior, $0 \mathrm{~mm}$ and $10 \mathrm{~mm}$ posterior. These positions are indicated schematically by the stump of the femur at the left of each column. The actual targets for the rear leg, the positions of the middle leg tarsus, are plotted as black dots. Connected to each target position are the respective endpoints of the hind leg protraction before (crosses) and after (squares) removal of the sense organs indicated. For details see text and Tables 1-3. Arrows at lower right show the orientation of the $\mathrm{x}$ and $\mathrm{y}$ axes in HR1 is increased by increased adduction. At the extremes of abduction and adduction, these hairs may be all uncovered or all under the sternal margin regardless of retraction angle. For normal coxa positions the number of deflected hairs is not a monotonic function of leg retraction but is slightly greater for posterior leg positions.

In summary, HR1-4 act in opposition to cxHPd, cxHPv, and the trochantin hairs with respect to protraction and retraction. The cxHPd acts in opposition to HR1 and the trochantin hairs with respect to abduction and adduction of the coxa.

Compared to the subcoxal joint, the coxa-trochanter joint is very simple. This dicondylic joint permits rotation about a single axis perpendicular to the femur-tibia plane (Cruse 1976). Rotation at this joint elevates and depresses the trochanterofemur. Joint position is measured by the trochanteral hairplate, trHP (Wendler 1964). Elevation above the axis of the coxa causes the joint membrane to cover more hairs in trHP G2. The hairs of trHP G1, which stand in continual contact with the joint membrane, presumably are able to signal the full range of joint positions through changes in spike frequency.

\section{Ablation of all hairplates and of all hair rows}

With the above anatomical background, behavioural experiments were carried out to test the extent to which these sense organs of the middle leg guide the swing movement of the ipsilateral hind leg. For this purpose the different hairplates and hair rows were ablated and the influence of the ablation on the movement of the hind leg was measured. In the first series of experiments all three hairplates - cxHPd, cHPv (including the hairs on the trochantin) and trHP - were ablated. Postoperative observation of the animal walking free on a horizontal plane qualitatively confirmed that the range of movement of the middle leg is shifted in the anterior direction (see also Wendler 1964; Bässler 1977; Dean and Wendler 1983, for stick insects; see Wong and Pearson 1976, for cockroaches). The anterior extreme position of the middle leg often was in front of the posterior extreme position of the front leg. The distance between posterior extreme positions of the middle leg and anterior extreme positions of the hind leg was increased compared to that of the intact side of the animal.

Using the platform, measurements of the endpoints of hind leg protraction were recorded with the operated middle leg at 'zero', $10 \mathrm{~mm}$ anterior and $10 \mathrm{~mm}$ posterior. For the latter two measurements, the same three animals were used. The mean location of hind leg placement relative to the middle leg before and after operation are shown in Fig. 2a. Standard deviations, sample size, number of animals and the change in placement due to the operation are given in Table 1 . The differences in the lateral direction $(x)$ were small and not significant $(P>0.1)$. In the longitudinal direction $(y)$, a caudal shift of the hindleg endpoint was obvious and significant $(P \leqq 0.001)$. The magnitude of this caudal shift was similar for all three target positions. For two positions $-10 \mathrm{~mm}$ anterior and $10 \mathrm{~mm}$ posterior - the experiment was repeated with removal of the cxHPv alone, leaving the trochantinal hairs and other hairplates. The differences in the longitudinal direction were $2.6 \mathrm{~mm}$ and $2.1 \mathrm{~mm}$, respectively. A postmeasurement examination with SEM revealed that about $50 \%$ of the $\operatorname{cxHPv}$ G1 hairs were not fully ablated, al- 
Table 1. Change in rear leg endpoint position following removal of cxHPv, cxHPd and trHP for three different positions of the middle leg. The position of the hind leg is measured relative to that of the middle leg $(0,0)$ in $\mathrm{mm} ; x$ and $y$ are positive for more lateral and more posterior positions, respectively. The table lists means and standard deviations, the sample size $(n)$ and the number of animals (an) for each target position. The difference, $\Delta$, between mean values of intact and operated animals shows the change due to the operation; this change is uninfluenced by middle leg position

\begin{tabular}{|c|c|c|c|c|}
\hline \multirow{2}{*}{$\begin{array}{l}\text { Middle leg } \\
\text { position }\end{array}$} & \multicolumn{3}{|c|}{ Rear leg step endpoint } & \multirow[t]{2}{*}{$\Delta$} \\
\hline & & Intact & $\begin{array}{l}\text { Middle leg } \\
\text { operation } \\
\text { cxHPv, cxHPd, } \\
\text { trHP }\end{array}$ & \\
\hline \multirow{2}{*}{$\begin{array}{l}10 \mathrm{~mm} \\
\text { anterior }\end{array}$} & $x$ & $1.4 \pm 1.3$ & $2.1 \pm 1.6$ & 0.7 \\
\hline & $y$ & $\begin{array}{l}3.4 \pm 1.5 \\
n=60, \text { an }=3\end{array}$ & $\begin{array}{l}7.4 \pm 2.4 \\
n=160, a n=3\end{array}$ & 4.0 \\
\hline \multirow[t]{2}{*}{$0 \mathrm{~mm}$} & $x$ & $2.0 \pm 1.8$ & $1.6 \pm 2.1$ & -0.4 \\
\hline & $y$ & $\begin{array}{l}3.6 \pm 2.6 \\
n=223, a n=7\end{array}$ & $\begin{array}{l}8.0 \pm 3.0 \\
n=326, a n=7\end{array}$ & 4.4 \\
\hline \multirow{2}{*}{$\begin{array}{l}10 \mathrm{~mm} \\
\text { posterior }\end{array}$} & $x$ & $1.2 \pm 1.9$ & $1.2 \pm 1.6$ & 0 \\
\hline & $y$ & $\begin{array}{l}3.7 \pm 1.8 \\
n=60, \text { an }=3\end{array}$ & $\begin{array}{l}7.9 \pm 2.3 \\
n=160, a n=3\end{array}$ & 4.2 \\
\hline
\end{tabular}

Table 2. Change in rear leg endpoint position following removal of HR1- 4 for three different positions of the middle leg. The format is the same as that of Table 1. The magnitude of the change, $\Delta$, in anterior-posterior position $(y)$ is not significantly different for the three middle leg positions

\begin{tabular}{|c|c|c|c|c|}
\hline \multirow{2}{*}{$\begin{array}{l}\text { Middle leg } \\
\text { position }\end{array}$} & \multicolumn{3}{|c|}{ Rear leg step endpoint } & \multirow[t]{2}{*}{$\Delta$} \\
\hline & & Intact & $\begin{array}{l}\text { Middle leg } \\
\text { operation } \\
\text { HR1-4 }\end{array}$ & \\
\hline \multirow{2}{*}{$\begin{array}{l}10 \mathrm{~mm} \\
\text { anterior }\end{array}$} & $x$ & $1.9 \pm 1.5$ & $2.0 \pm 1.7$ & 0.1 \\
\hline & $y$ & $\begin{array}{l}2.9 \pm 1.5 \\
n=100, a n=4\end{array}$ & $\begin{array}{l}2.3 \pm 1.4 \\
n=81, \text { an }=4\end{array}$ & -0.6 \\
\hline \multirow[t]{2}{*}{$0 \mathrm{~mm}$} & $x$ & $2.0 \pm 1.7$ & $2.1 \pm 1.7$ & 0.1 \\
\hline & $y$ & $\begin{array}{l}3.6 \pm 2.4 \\
n=203, \text { an }=7\end{array}$ & $\begin{array}{l}1.9 \pm 2.2 \\
n=254, a n=7\end{array}$ & -1.7 \\
\hline \multirow{2}{*}{$\begin{array}{l}10 \mathrm{~mm} \\
\text { posterior }\end{array}$} & $x$ & $1.6 \pm 1.6$ & $3.0 \pm 2.2$ & 1.4 \\
\hline & $y$ & $\begin{array}{l}3.3 \pm 2.1 \\
n=158, \text { an }=7\end{array}$ & $\begin{array}{l}2.0 \pm 2.7 \\
n=247, a n=7\end{array}$ & -1.3 \\
\hline
\end{tabular}

though a special effort was made to ablate the groove in which these hairs stand.

After all four hair rows on the posterior surface of the coxa were ablated, animals walking free or on the treadwheel often placed the hind leg of the operated side in front of the middle leg. This only
Table 3. Combined effect of hairplate (cxHPv, cxHPd, trHP) and hair row (HR1-4) ablation for three different positions of the middle leg. The magnitude of the change, $\Delta$, in $y$ is a combination of the individual effects shown in Tables 1 and 2

\begin{tabular}{lllll}
\hline $\begin{array}{l}\text { Middle leg } \\
\text { position }\end{array}$ & \multicolumn{2}{c}{ Rear leg step endpoint } & \multirow{2}{*}{$\Delta$} \\
\cline { 2 - 4 } & & Intact & $\begin{array}{l}\text { Middle leg } \\
\text { operation } \\
\text { cxHPv, cxHPd, } \\
\text { trHP, HR1-4 }\end{array}$ & \\
\hline $10 \mathrm{~mm}$ & $x$ & $1.9 \pm 1.5$ & $3.1 \pm 1.9$ & 1.2 \\
anterior & $y$ & $2.9 \pm 1.5$ & $\begin{array}{l}5.9 \pm 2.2 \\
n=100, \text { an }=4\end{array}$ & 3.0 \\
& & $n=120$, an $=4$ & \\
$0 \mathrm{~mm}$ & $x$ & $1.9 \pm 1.6$ & $2.6 \pm 2.5$ & 0.7 \\
& $y$ & $3.8 \pm 2.4$ & $5.9 \pm 3.7$ & 2.1 \\
& & $n=143$, an & $n=153$, an $=7$ & \\
$10 \mathrm{~mm}$ & $x$ & $1.7 \pm 1.6$ & $2.2 \pm 2.4$ & 0.5 \\
posterior & $y$ & $3.0 \pm 1.9$ & $5.2 \pm 3.3$ & 2.2 \\
& & $n=98$, an $=5$ & $n=138$, an $=5$ & \\
\hline
\end{tabular}

rarely happened on the intact side (see also Bässler 1977). The same three middle leg positions were used as in the first experiment and the results are shown in Fig. $2 \mathrm{~b}$ and Table 2. Except for one position, $10 \mathrm{~mm}$ posterior, there were no significant differences in the transverse direction. In the longitudinal direction the target point of the hind leg after the middle leg operation was shifted anteriorly but this was significant only for the middle leg positions, 'zero' and ' $10 \mathrm{~mm}$ posterior' $(P \leqq$ 0.01 ).

Finally all three hairplates and four hair rows were ablated. The results are shown in Fig. $2 \mathrm{c}$ and in Table 3. Again the differences in the transverse direction were small, whereas those in the longitudinal direction were obvious and significant. For all three target positions, the hind leg endpoint appeared to be shifted backwards by about the same amount. However, this shift was smaller than that occurring when only the three hairplates were ablated. It was smaller by an amount exceeding the change obtained when the hair rows alone were ablated.

\section{Ablation of individual hairplates}

In the following series of experiments the relative contributions of the individual hairplates were investigated. Only position 'zero' was measured. As shown in Fig. 3 and Table 4, five conditions were tested in which the following organs were ablated: (1) ventral coxal hairplate (cxHPv), (2) dorsal 


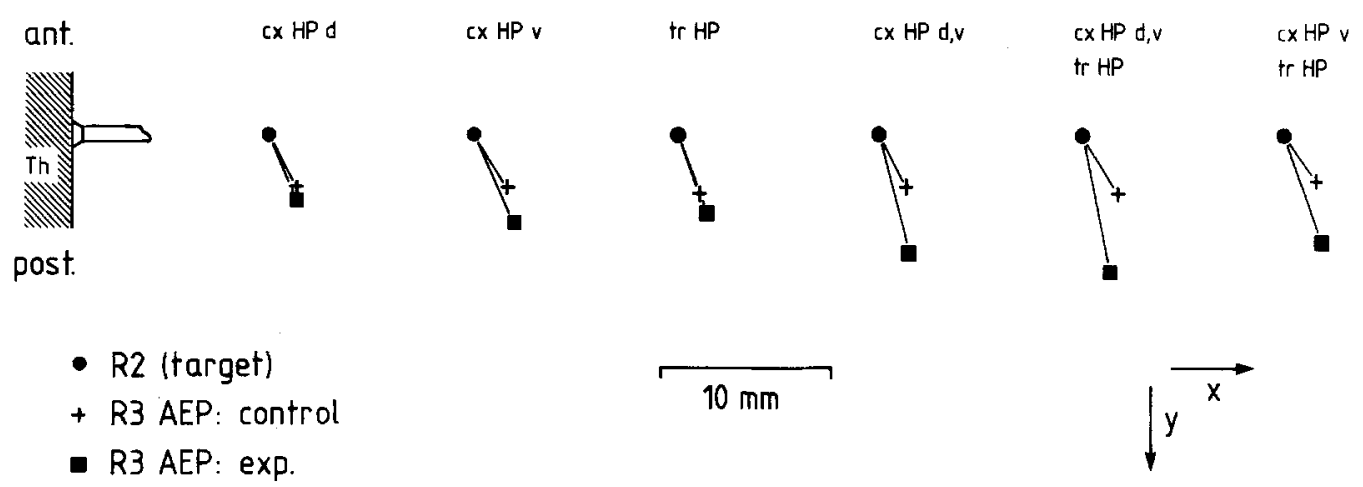

Fig. 3. Combined effect of individual hairplates. Results are presented as in Fig. 2, but here for each experimental condition, the middle leg was tested only at the middle position $(0 \mathrm{~mm})$. Connected to this target position (dots) are the respective endpoints of the hindleg protraction before (crosses) and after (squares) removal of the sense organs indicated above each set of results. Only the leftmost target position is shown in correct relation to the thorax $(T h)$; the others are displaced from this position for the sake of clarity. For details see text and Table 4

Table 4. Change in rear leg endpoint position following ablation of different combinations of middle leg hairplates. All measurements are for the middle leg at its 'zero' position. The format is otherwise that of Table 1. For further explanation see text

\begin{tabular}{|c|c|c|c|c|}
\hline \multirow{2}{*}{$\begin{array}{l}\text { Middle leg } \\
\text { operation }\end{array}$} & \multicolumn{3}{|c|}{ Rear leg step endpoint } & \multirow[t]{2}{*}{$\Delta$} \\
\hline & & Intact & Operated & \\
\hline \multirow[t]{2}{*}{$\mathrm{cxHPv}$} & $x$ & $1.9 \pm 1.7$ & $2.2 \pm 1.6$ & 0.3 \\
\hline & $y$ & $\begin{array}{l}3.3 \pm 1.8 \\
n=60, a n=3\end{array}$ & $\begin{array}{l}5.3 \pm 2.4 \\
n=180, \text { an }=3\end{array}$ & 2.0 \\
\hline \multirow[t]{2}{*}{ cxHPd } & $x$ & $1.7 \pm 1.5$ & $1.6 \pm 1.6$ & -0.1 \\
\hline & $y$ & $\begin{array}{l}3.2 \pm 2.3 \\
n=80, a n=4\end{array}$ & $\begin{array}{l}3.8 \pm 1.9 \\
n=220, a n=4\end{array}$ & 0.6 \\
\hline \multirow[t]{2}{*}{$\operatorname{trHP}$} & $x$ & $1.5 \pm 1.5$ & $1.7 \pm 1.6$ & 0.2 \\
\hline & $y$ & $\begin{array}{l}3.5 \pm 2.2 \\
n=160, a n=8\end{array}$ & $\begin{array}{l}4.6 \pm 2.3 \\
n=260, a n=8\end{array}$ & 1.1 \\
\hline \multirow[t]{2}{*}{$\mathrm{cxHPv}, \mathrm{d}$} & $x$ & $1.6 \pm 1.6$ & $1.8 \pm 1.6$ & 0.2 \\
\hline & $y$ & $\begin{array}{l}3.2 \pm 1.9 \\
n=100, a n=5\end{array}$ & $\begin{array}{l}7.0 \pm 2.5 \\
n=280, a n=5\end{array}$ & 3.8 \\
\hline \multirow{2}{*}{$\begin{array}{l}\text { cxHPv, } \\
\text { trHP }\end{array}$} & $x$ & $2.1 \pm 2.0$ & $2.3 \pm 2.3$ & 0.2 \\
\hline & $y$ & $\begin{array}{l}2.8 \pm 1.7 \\
n=77, a n=4\end{array}$ & $\begin{array}{l}6.2 \pm 3.0 \\
n=119, \text { an }=4\end{array}$ & 3.4 \\
\hline
\end{tabular}

coxal hairplate (cxHPd), (3) trochanteral hairplate (trHP), (4) both coxal hairplates and (5) ventral coxal and trochanteral hairplate. For comparison, Fig. 3 also includes the earlier result for ablation of all three hairplates. As in most of the earlier experiments, no significant differences were found between operated animals and controls in the lateral direction. In the longitudinal direction the apparent target point for the hind leg was shifted caudally in all cases. The size of the shift depended
Table 5. Trajectory of the hind leg for the 'zero' position of the middle leg before and after ablation of the trochanteral hairplate. Results were obtained by measuring the touch down of the hind leg on the platform positioned at different platform heights as given in the table. Removal of the trHP apparently shifts the whole trajectory ventrally. For further explanation see text

\begin{tabular}{|c|c|c|c|c|}
\hline \multirow{2}{*}{$\begin{array}{l}\text { Platform } \\
\text { height } \\
(\mathrm{mm})\end{array}$} & \multicolumn{3}{|c|}{ Rear leg step endpoint } & \multirow[t]{2}{*}{$\Delta$} \\
\hline & & Intact & $\begin{array}{l}\text { Middle leg } \\
\text { operation } \\
\text { trHP }\end{array}$ & \\
\hline \multirow[t]{2}{*}{+10} & $x$ & $1.7 \pm 1.7$ & & \\
\hline & $y$ & $\begin{array}{l}7.3 \pm 3.4 \\
n=100, \text { an }=3\end{array}$ & & \\
\hline \multirow[t]{2}{*}{+5} & $x$ & $2.2 \pm 1.2$ & $2.1 \pm 1.4$ & -0.1 \\
\hline & $y$ & $\begin{array}{l}4.3+2.2 \\
n=120, \text { an }=3\end{array}$ & $\begin{array}{l}5.6 \pm 2.1 \\
n=100, a n=3\end{array}$ & 1.3 \\
\hline \multirow[t]{2}{*}{0} & $x$ & $2.1 \pm 1.4$ & $2.3 \pm 1.4$ & 0.2 \\
\hline & $y$ & $\begin{array}{l}3.1 \pm 1.5 \\
n=202, a n=6\end{array}$ & $\begin{array}{l}4.8 \pm 1.5 \\
n=100, a n=3\end{array}$ & 1.7 \\
\hline \multirow[t]{2}{*}{-5} & $x$ & $2.0 \pm 1.3$ & $2.1 \pm 1.3$ & 0.1 \\
\hline & $y$ & $\begin{array}{l}1.7 \pm 1.3 \\
n=124, a n=3\end{array}$ & $\begin{array}{l}2.6 \pm 1.1 \\
n=100, a n=3\end{array}$ & 0.9 \\
\hline \multirow[t]{2}{*}{-10} & $x$ & $1.4 \pm 1.1$ & & \\
\hline & $y$ & $\begin{array}{l}-0.7 \pm 1.5 \\
n=100, \text { an }=3\end{array}$ & & \\
\hline
\end{tabular}

upon the ablated hairplate. It was smallest and only weakly significant $(P \leqq 0.05)$ for ablation of the dorsal coxal hairplate. This agrees with results of Wendler (1964) who investigated the influence of a hairplate on the position of its own leg and found that of the three hairplates the dorsal coxal 


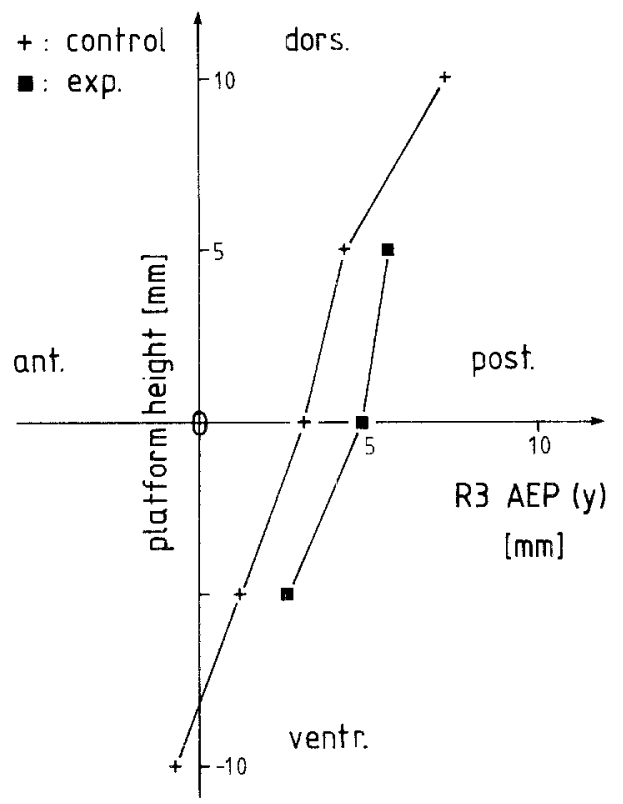

Fig. 4. Trajectory of the hind leg before and after ablation of the trochanteral hairplate. The leg movement is depicted as if viewed from the side. The tarsus of the middle leg, the target for the hind leg, is positioned at the origin. Data before (crosses) and after (squares) the operation were collected by recording the touch down point of the rear leg with the measuring platform at the heights indicated on the ordinate. The anteriorposterior coordinate $(y)$ is shown on the abscissa. For details see text and Table 5

hairplate produced the smallest effect. The largest change was caused by ablation of the ventral coxal hairplate, whereas ablation of the trochanteral hairplate produces an intermediate, but still significant shift in the posterior direction. When two or three hairplates were ablated, the combined effect increased and was larger than the sum of the changes obtained by ablation of the single hairplates. This result indicates a nonlinear interaction.

The caudal direction of the shifts produced by ablation of the coxal hairplates is to be expected on the basis of their morphological arrangement. However, because the trochanteral hairplate appears to measure only the height of the tarsus, ablation of this organ was not expected to produce any shift in the longitudinal direction. The caudal shift found here can be understood under the assumption that the ablation of the trochanteral hairplate moves the apparent target point ventrally and the trajectory of the hind leg in the final part of the swing phase is sloped. To test this hypothesis, the middle leg was again placed at the zero position, but the platform for measuring the arrival of the hind leg tarsus was positioned at different heights. Results are shown in Table 5 and Fig. 4. Three animals were measured with platform
Table 6. Effect of cutting the receptor apodeme of the femoral chordotonal organ (feCO) for two lateral positions of the middle leg. Unlike hairplate ablation, this operation affects primarily the lateral placement of the rear leg. For further explanation see text

\begin{tabular}{clllr}
\hline $\begin{array}{l}\text { Middle leg } \\
\text { position }\end{array}$ & \multicolumn{2}{c}{ Rear leg step endpoint } & \multirow{2}{*}{$A$} \\
\cline { 2 - 4 } & & Intact & $\begin{array}{l}\text { Middle leg } \\
\text { operation } \\
\text { feCO }\end{array}$ & \\
\hline 5 mm & $x$ & $3.8 \pm 2.8$ & $7.2 \pm 3.3$ & 3.4 \\
inside & $y$ & $4.5 \pm 3.3$ & $4.8 \pm 3.5$ & 0.3 \\
& & $n=120$, an $=8$ & $n=200$, an $=8$ & \\
5 mm & $x$ & $2.0 \pm 1.9$ & $1.1 \pm 2.3$ & -0.9 \\
outside & $y$ & $\begin{array}{l}3.0 \pm 2.7 \\
n=120, a n=8\end{array}$ & $\begin{array}{l}4.0 \pm 3.0 \\
n=192, a n=8\end{array}$ & 1.0 \\
\hline
\end{tabular}

heights of $+5 \mathrm{~mm}, 0 \mathrm{~mm}$ and $-5 \mathrm{~mm}$ (negative is below 0 ) before and after ablation of the trochanteral hairplate. Three other animals were measured intact at heights of $+10 \mathrm{~mm}, 0 \mathrm{~mm}$ and $-10 \mathrm{~mm}$. The results show that the final part of the swing movement is sloped (Fig. 4). Thus the caudal shift measured at the normal platform height after ablation of the trHP can be attributed to a shift in the target point by about $4 \mathrm{~mm}$ in the ventral direction.

\section{Cutting the receptor apodeme of the femoral chordotonal organ}

The femoral chordotonal organ measures the angle between femur and tibia. Since with the middle leg in the zero position this organ monitors the lateral distance between the tarsus and the body, the following two target positions of the middle leg were investigated. The tarsus was placed either $5 \mathrm{~mm}$ inside or $5 \mathrm{~mm}$ outside the zero position. The results (Table 6) show that for both middle leg positions the apparent target after cutting the receptor apodeme was nearer the zero position. The hind leg endpoint was less affected by but still dependent on changes in the lateral position of the middle leg. Only small changes were observed in the longitudinal $(y)$ direction.

In some of these animals the experiments were continued by ablating all three hairplates. The result (Table 7) of this combined experiment shows a summation of the effects from the single ablation experiments. Shifts in the transverse direction $(x)$ are like those in Table 6; shifts in the longitudinal direction $(y)$ are like those in Table 1. 
Table 7. Combined effect of cutting the receptor apodeme of the femoral chordotonal organ (feCO) and ablating three hairplates (cxHPv, cxHPd, trHP) for two lateral positions of the middle leg. The combined effect is a summation of the separate changes shown in Tables 1 and 6

\begin{tabular}{|c|c|c|c|c|}
\hline \multirow{2}{*}{$\begin{array}{l}\text { Middle leg } \\
\text { position }\end{array}$} & \multicolumn{3}{|c|}{ Rear leg step endpoint } & \multirow[t]{2}{*}{$\Delta$} \\
\hline & & Intact & $\begin{array}{l}\text { Middle leg } \\
\text { operation } \\
\text { cxHPv, cxHPd, } \\
\text { trHP, feCO }\end{array}$ & \\
\hline \multirow{2}{*}{$\begin{array}{l}5 \mathrm{~mm} \\
\text { inside }\end{array}$} & $x$ & $3.8 \pm 2.9$ & $7.1 \pm 3.2$ & 3.3 \\
\hline & $y$ & $\begin{array}{l}3.4 \pm 3.2 \\
n=75, a n=5\end{array}$ & $\begin{array}{l}7.8 \pm 3.7 \\
n=136, a n=5\end{array}$ & 4.4 \\
\hline \multirow{2}{*}{$5 \mathrm{~mm}$} & $x$ & $2.3 \pm 1.9$ & $1.2 \pm 2.1$ & -1.1 \\
\hline & $y$ & $\begin{array}{l}2.4+2.4 \\
n=75, a n=5\end{array}$ & $\begin{array}{l}6.2 \pm 4.0 \\
n=134, \text { an }=5\end{array}$ & 3.8 \\
\hline
\end{tabular}

\section{Covering sensory hairs with wax}

When the hairs were covered with wax to eliminate sensory inputs (see Dean and Wendler 1983), the sensory hairs remained intact. When hair rows $2-4$ were covered, the hind leg continued to follow the middle leg position closely but with a constant shift. This indicates that the modified input to the CNS was the same for waxing as for ablation of hair rows [Presumably spike activity was absent because the sensory cells do not spike when the hairs are not flexed (Dean, in preparation)].

However, when the hairplates were covered with wax most animals behaved very differently, even when walking on a flat surface. After the hairplates are ablated, the gross behaviour of the leg is normal except for quantitative changes in some extreme values (Wendler 1964; Bässler 1977). After the cxHPv is covered with wax, the femur of this leg is held continuously in a raised and extremely anterior position with the femur-tibia joint somewhat flexed. Therefore the tarsus of this leg is held under the body and very rarely touches the ground. When the trHP is covered with wax, the femur is raised and the femur-tibia joint is more or less extended. The animal walks with the middle leg 'saluting' as described by Graham and Bässler (1981) after crossing the receptor apodeme of the femoral chordotonal organ. This effect could also be produced when the coxa was touched near the cxHPv by a hot wire without wax. Therefore this effect appears to result from overheating unidentified structures at the coxa. With these animals the measurements could not be performed in the same way as before, because the middle leg no longer grasped or remained standing on the platform. We
Table 8. Effect of covering three hairplates (cxHPv, cxHPd, trHP) with wax for two positions of the middle leg. Unlike the results shown in Table 1 for hairplate ablation, the change, $\Delta$, in $y$ depends on middle leg position

\begin{tabular}{cllll}
\hline $\begin{array}{l}\text { Middle leg } \\
\text { position }\end{array}$ & \multicolumn{2}{c}{ Rear leg step endpoint } & \multirow{3}{*}{$\Delta$} \\
\cline { 2 - 4 } & & Intact & $\begin{array}{l}\text { Middle leg } \\
\text { cxHPv, cxHPd, } \\
\text { trHP waxed }\end{array}$ & \\
\hline $10 \mathrm{~mm}$ & $x$ & $2.9 \pm 2.8$ & $4.9 \pm 3.3$ & 2.0 \\
anterior & $y$ & $4.3 \pm 2.8$ & $10.0 \pm 3.9$ & 6.7 \\
& & $n=45$, an $=3$ & $n=90$, an $=3$ & \\
10 mm & $x$ & $1.5 \pm 1.8$ & $3.3 \pm 3.5$ & 1.8 \\
posterior & $y$ & $3.9 \pm 2.5$ & $3.9 \pm 5.0$ & 0 \\
& & $n=45$, an $=3$ & $n=90$, an $=3$ & \\
\hline
\end{tabular}

had to restrain the operated middle leg with a rod held lightly on the tarsus. By this procedure we obtained the results shown in Table 8 . The rear leg continued to adjust its landing point in the longitudinal $(y)$ direction to the absolute position of the middle leg but to a much smaller degree than when the hairplates had been ablated. The very different behaviour of the animals means that the results of the waxing experiments are not comparable with those obtained from animals with their sensory hairs ablated.

\section{Discussion}

The experiments were performed to examine the role of different sense organs of the middle leg in controlling the targeting movement of the ipsilateral hind leg during walking. Qualitatively, the results of the ablations show that all the sense organs tested - the two coxal hairplates, the trochanteral hairplate, the coxal hair rows and the femoral chordotonal organ - supply information used by the CNS to calculate the target point for the hind leg protraction. This control pathway exhibits several features. First, these intersegmental pathways apparently function only during walking. In standing animals, signals from the sensory hair organs influence the position of the leg on which they are located, but they have no effect on adjacent legs (Wendler 1964). This behaviour is another example of a neural circuit that is active in only one behaviour or the corresponding internal state (Bässler 1977).

Second, in all operated animals, even those for which all the external proprioceptors considered here were ablated, the actual position of the middle leg retained some influence on the target of the 
hind leg. Thus there must be still other sense organs from which the hind leg receives information on the position of the middle leg. This is not surprising in view of the plethora of mechanoreceptors found both internally and externally at the proximal joints of locusts (Hustert 1983). One can assume that the situation is basically the same in stick insects (Hustert, personal communication).

Third, the directions of the changes elicited by ablating specific organs were as expected from their morphological arrangement. For the hair sense organs, it was assumed that ablation or covering with wax corresponded to fixing the hairs in an upright position and that the apparent target for the hind leg would therefore shift towards middle leg positions in which the intact organ is normally unstimulated. This was true in all cases. For the chordotonal organ, one can assume that cutting the receptor apodeme removes most phasic input but may leave a tonic signal corresponding to an undetermined femur-tibia angle. The results indicate that this tonic signal corresponds to an angle of about $90^{\circ}$.

Cutting or covering sensory hairs at the two proximal joints elicited significant and consistent changes only in the anterior-posterior placement of the rear leg. Thus, for the middle leg positions tested here, the false afferent information from these two joints - the subcoxal and the coxal-trochanteral - primarily signalled longitudinal and vertical tarsal changes, respectively. The reverse was true for cutting the receptor apodeme of the femoral chordotonal organ. Transverse changes were significant, whereas longitudinal shifts were slight. For the middle leg positions tested here rotation of the femur-tibia joint primarily translates into lateral tarsal motion. Both these relations hold anatomically only for intermediate positions of the middle leg.

Quantitative experimental results for hair ablation showed the following properties: (1) When several sense organs at one joint were ablated, the total effect was usually larger than the sum of the effects when the sense organs were ablated individually (Table 4, Fig. 3). (2) Each operation evoked a nearly constant deviation from the control value, which was independent of the actual position of the middle leg (Tables 1-3, Fig. 2).

What can one conclude from these results concerning the integration of the signals from the different sense organs? Integration across several joints proceeds additively and orthogonally. The orthogonal shifts due to chordotonal ablation and hairplate ablation sum vectorially when the two ablations are combined. Similarly the trHP effect can be attributed to addition of a vertical shift in the position of the apparent target.

The integrative mechanism is less straightforward at the subcoxal joint, where multiple proprioceptors contribute information. For the sake of simplificity we refer to joint angle instead of tarsus position as the measured parameter. The starting assumption is that the four hair rows and the two hairplates each compute a measure for the joint angle and send this value to the CNS. Differences in the polarity of leg movement producing increasing activity will be neglected for the moment. There are several hypotheses for how these separate values are combined.

First, when several sense organs measure the same parameter, the simplest combination might be to calculate a mean value in the sense of an arithmetic mean. However, the following consideration shows that this mechanism does not agree with our results. If a single ablated sense organ, e.g. the ventral coxal hairplate, signals a very large angle, while the remaining intact sense organs measure the real position, then the error in the computed average should depend on the actual position of the leg and should be larger the farther the actual leg position is from the angle signalled by the ablated organ. This was not found (Fig. 2). Another possibility is that only one of the several sense organs measuring the same parameter is normally functional. The CNS could monitor those organs that are 'functional' and disregard others, e.g. those providing an unchanging signal. According to this hypothesis, no effect should be found after ablation of only one sense organ. This was not the case.

A third possibility is that the different sense organs are not really connected in parallel but that each monitors a different range of leg position. Two forms of this so-called range fractionation need to be considered separately: (1) The active range of a given sense organ covers only acute angles, e.g. anterior tarsus positions for the $\mathrm{cxHPv}$ G2. Ablation of this sense organ should not affect the results for large and medium angles because the hairs of the intact sense organ are not normally deflected at these positions and ablation should not alter the input to the CNS. The results of our ablation experiments contradict this prediction (however, see results of Table 8 for wax immobilisation). (2) The active range of the sense organ covers only obtuse angles, e.g. posterior tarsus positions for the cxHPv. In this case the hairs of the intact sense organ are fully deflected for smaller angles and respond differentially only for obtuse angles. Thus ablation of these hairs would produce 
a constant error in all but the very posterior ranges. Under some special assumptions our results could therefore agree with this hypothesis but the morphological results make it improbable. Differential deflection of the hair rows is spread over nearly the whole range of leg positions. Similarly, most hairs of the ventral coxal hairplate are flexed only in the anterior half of leg range, i.e. for acute and medium angles that could only fit the assumption in (1).

Therefore the question remains as to how the signals from the diverse proprioceptors at the subcoxal joint are integrated. Our findings best fit the following qualitative model which was based on two findings: (1) all sense organs contribute to the final signal determining the target point and (2) the effects of the different sense organs sum qualitatively (see Fig. 2, for hairplates and hair rows; Fig. 3 for combinations of different hairplates). Thus one has to conclude that some kind of mean value is calculated, but it must be nonlinear. The linear model discussed and rejected above requires that ablation of an organ results in greater deviations for small leg angles than for large ones because for large leg angles the difference between the signal of the operated sense organ and those of the other intact organs is small. However, the experimentally measured deviation was about the same for all actual angles measured; this was particularly true for ablation of hairplates. This means that the influence of the ablated sense organ is small for small angles and increases with angle size. This might be interpreted as follows. The signals from all sense organs are used to calculate a mean value, but the more the signal of one sense organ deviates from the signals of the majority the less it is weighted. Such a suppression of divergent signals is biologically sensible as it would enable the CNS to disregard anomalous values to some extent. A similar procedure is also used in statistics when the median is applied instead of the arithmetic mean. Since the differences found after ablation of the hair rows are small and could depend upon middle leg position although with a very small slope, a weak linear influence of the hair rows cannot be excluded.

As mentioned above, ablation of sensory hairs in the inner group (G1) of the cxHPv was incomplete. Because the hairs of G1 are always deflected by the joint membrane, differential deflection might occur either over the whole range of movement or, more probably, only for obtuse angles. In the latter case the incompletely ablated hairplate should signal a constant angle for most rostral leg angles. This constant value can be treated as equiv- alent to the constant output of a fully ablated organ for the purpose of the above arguments. In the former case the hairs remaining in G1 can be considered as one of the other intact sense organs. In either case the conclusions are not altered by the incompleteness of the operation.

Finally it should be discussed whether the targeting behaviour measured here for the initial hind leg step is also a feature of walking. Several observations support this interpretation. Graham and Bässler (1981) investigated animals with the receptor apodeme of the femoral chordotonal organ crossed in the middle leg. Following this operation, the chordotonal organ records the femur-tibia joint as being extended when it is flexed and vice versa. The hind leg of the walking animal often searches for contact $1-2 \mathrm{~cm}$ lateral to the rim of the treadwheel, indicating that it expects to find the tarsus of the middle leg at this position. In our experiments when the platform with the middle leg was very far in front, the hind leg could not reach it. During walking the hind leg then made continuous grasping movements in the direction of the middle leg position during several steps of the other legs. Recent experiments of Dean and Wendler (1983) showed clearly that the targeting behaviour is present in the continuously walking animal. They found significant correlation coefficients between the position of the protraction endpoint of each hind leg and the simultaneous position of the ipsilateral middle leg in intact stick insects walking on a treadwheel with all six legs. Immobilisation of the sensory hairs of the coxal hairplates and hair rows by wax qualitatively showed that these sense organs contribute to the targeting behaviour. The correlation coefficients decreased strongly after immobilisation. This agrees with our results showing that the hind leg endpoint was less dependent upon the absolute position of the middle leg when the hairplates were waxed (Table 8 ). Furthermore, the direction of changes in the placement of the rear leg relative to the ipsilateral middle leg are consistent with the findings reported here.

Acknowledgements. We want to express our thanks to U. Galbraith for making the drawings and performing some of the experiments.

\section{References}

Bässler U (1965) Proprioreceptoren am Subcoxal- und FemurTibia-Gelenk der Stabheuschrecke und ihre Rolle bei der Wahrnehmung der Schwerkraftrichtung. Kybernetik 2:168-193

Bässler U (1977) Sensory control of leg movement in the stick insect Carausius morosus. Biol Cybern 25:61-72 
Bräunig P, Hustert R, Pflüger H-J (1981) Distribution and specific central projections of mechanoreceptors in the thorax and proximal leg joints of locusts. I. Morphology, location and innervation of internal proprioceptors of pro- and metathorax and their central projections. Cell Tissue Res 216:57-77

Cruse $H$ (1976) On the function of the legs in the free walking stick insect Carausius morosus. J Comp Physiol 112:235-262

Cruse $H$ (1979) The control of the anterior extreme position of the hindleg of a walking insect. Physiol Entomol 4:121-124

Cruse H, Pflüger H-J (1981) Is the position of the femur-tibia joint under feedback control in the walking stick insect? II. Electrophysiological recordings. J Exp Biol 92:97-107

Dean J, Wendler G (1983) Stick insect locomotion on a walking wheel: interleg coordination of leg position. J Exp Biol 103: 75-94

Fourtner CH, Evoy WH (1973) Nervous control of walking in the crab Cardisoma guanhumi. IV. Effects of myochordotonal organ ablation. J Comp Physiol 83:319-329

Graham D, Bässler U (1981) Effects of afference sign reversal on motor activity in walking stick insects (Carausius morosus). J Exp Biol 91:179-193

Graham D, Wendler G (1981) Motor output to the protractor and retractor muscles in a stick insect walking on a treadwheel. Physiol Entomol 6:161-174
Hustert R (1983) Proprioceptor responses and convergence of proprioceptive influence on motoneurones in the mesothoracic thoraco-coxal joint of locust. J Comp Physiol 150:77-86

Hustert R, Pflüger H-J, Bräunig P (1981) Distribution and specific central projections in the thorax and proximal leg joints of locusts. III. The external mechanoreceptors: The campaniform sensilla. Cell Tissue Res 216:97-111

Pflüger H-J, Bräunig P, Hustert R (1981) Distribution and specific central projections of mechanoreceptors in the thorax and proximal leg joints of locusts. II. The external mechanoreceptors: Hair plates and tactile hairs. Cell Tissue Res 216:79-96

Suilmann M (1981) Der Einfluss der Sinnesborsten des Mittelbeines auf die vordere Extremstellung des ipsilateralen Hinterbeines der Stabheuschrecke Carausius morosus. Examensarbeit, Universität Kaiserslautern

Tatar G (1976) Mechanische Sinnesorgane an den Beinen der Stabheuschrecke Carausius morosus. Diplomarbeit, Universität Köln

Wendler G (1964) Laufen und Stehen der Stabheuschrecke: Sinnesborsten in den Beingelenken als Glieder von Regelkreisen. Z Vergl Physiol 48:198-250

Wong R, Pearson KG (1976) Properties of the trochanteral hair plate and its function in the control of walking in the cockroach. J Exp Biol 64:233-249 